\title{
Identification of endoscopic factors that predict poor responses to steroids in patients with gastrointestinal acute graft-versus-host disease
}

\author{
Kaoru Morita ${ }^{1}$ - Shin-ichiro Fujiwara ${ }^{1} \cdot$ Takashi Ikeda $^{1} \cdot$ Shin-ichiro Kawaguchi ${ }^{1} \cdot$ Yumiko Toda $^{1} \cdot$ Shoko $^{\text {Ito }}{ }^{1}$. \\ Takashi Nagayama ${ }^{1} \cdot$ Kiyomi Mashima ${ }^{1}{ }^{1} \cdot$ Kento Umino $^{1} \cdot$ Daisuke Minakata $^{1} \cdot$ Hirofumi Nakano ${ }^{1}$ • \\ Ryoko Yamasaki ${ }^{1} \cdot$ Masahiro Ashizawa ${ }^{1} \cdot{\text { Chihiro Yamamoto } \mathbb{D}^{1} \cdot \text { Kaoru Hatano }}^{1} \cdot$ Kazuya Sato $^{1} \cdot$ lekuni Oh $^{1}$. \\ Ken Ohmine ${ }^{1} \cdot$ Yoshinobu Kanda (iD ${ }^{1}$
}

Received: 27 May 2020 / Revised: 1 October 2020 / Accepted: 19 October 2020 / Published online: 2 November 2020

(c) The Author(s), under exclusive licence to Springer Nature Limited 2020

\begin{abstract}
Gastrointestinal acute graft-versus-host disease (aGVHD) is a life-threatening complication that requires urgent and appropriate treatment. An endoscopic examination is considered the gold-standard for the diagnosis of gastrointestinal aGVHD. However, the prognostic value of endoscopy remains controversial. This study aimed to investigate the usefulness of pre-treatment macroscopic and histopathologic findings of upper and lower endoscopy with respect to predicting steroidresistant gastrointestinal aGVHD. This retrospective study included 44 patients with gastrointestinal aGVHD who underwent endoscopy at the time of diagnosis and received systemic steroid treatment at our hospital. We graded the macroscopic and histopathologic findings using a previously validated 4-point scale. Univariate analyses of endoscopic grading revealed that a higher macroscopic grade in the ileum and higher histopathologic grades in the ileum and colon predicted a poor response to systemic steroids. In a multivariate analysis, macroscopic and histopathologic severity in the ileum were identified as significant prognostic factors that indicated resistance to steroid therapy. The presence of granulation tissue was also a strong independent predictor of resistance to steroid therapy. These findings suggest that both macroscopic and histopathologic findings in the ileum may be useful predictors of steroid-refractory gastrointestinal aGVHD and can indicate an immediate need to develop a second-line strategy.
\end{abstract}

Gastrointestinal acute graft-versus-host disease (aGVHD) is a life-threatening complication that requires urgent and appropriate treatment. An endoscopic examination is considered the gold-standard for the diagnosis of gastrointestinal aGVHD. To date, several investigators have studied the potential associations of endoscopic findings with the prognosis. Studies of upper endoscopy findings have determined that an infiltration of neutrophils or eosinophils, increased numbers of apoptotic cells, and low

Supplementary information The online version of this article (https:// doi.org/10.1038/s41409-020-01096-7) contains supplementary material, which is available to authorized users.

Yoshinobu Kanda ycanda-tky@umin.ac.jp

1 Division of Hematology, Department of Medicine, Jichi Medical University, Shimotsuke, Japan numbers of Paneth cells in the duodenum predicted disease severity [1-3]. Studies of lower endoscopy findings showed that the presence of colonic crypt loss and villous atrophy in the terminal ileum were correlated with responses to steroids [4, 5]. However, no consensus has been reached regarding which gastrointestinal tract segment is the strongest predictor of steroid resistance. Therefore, this study aimed to evaluate macroscopic and histopathologic endoscopy findings from all segments of the gastrointestinal tract and determine which segment of the upper and lower gastrointestinal tract is most useful for predicting a refractory response to systemic steroid therapy.

We retrospectively analyzed patients who underwent upper endoscopy and/or lower endoscopy because of suspected gastrointestinal aGVHD, received a clinical diagnosis of grade II-IV gastrointestinal aGVHD, and were initially treated with systemic steroids at Jichi Medical University Hospital from 2005 to 2019. The indications for endoscopy included diarrhea, nausea, and vomiting that could 
not be explained by other causes. The endoscopy assessment included five anatomic regions: stomach (fundus, body, antrum, and pylorus), duodenum (bulb and descending part), terminal ileum, colon (descending, transverse, descending, and sigmoid colon), and rectum. Biopsies were collected from each of these sites. At least two biopsies were sampled even if the tissue appeared macroscopically normal. Macroscopic and histopathologic findings were graded using a 4-point scale adapted from Cruz-Correa et al. [6] (Supplementary Fig. 1a-d). Endoscopic results were used to increase diagnostic confidence and to exclude other etiologies. Steroidrefractory disease was defined as aGVHD progression within 3 days of corticosteroid therapy (dosage: $1-2 \mathrm{mg}$ prednisone/ $\mathrm{kg} / \mathrm{day}$ ) or failure to improve after 7 days of corticosteroid therapy. This retrospective analysis was conducted after receiving approval from the Institutional Review Board of Jichi Medical University.

Of the 668 total HSCT procedures performed during the study period, 245 (37\%) patients were diagnosed with aGVHD. Among these 245 patients, 44 were diagnosed with grade II-IV gastrointestinal aGVHD via endoscopic evaluation and received systemic steroids as an initial treatment. Of these 44 patients, $24(55 \%)$ responded to steroid therapy (steroid-responsive group), whereas the other $20(45 \%)$ failed to achieve an adequate response (steroid-refractory group). The baseline characteristics of the recipients and donors are summarized in Table 1. At baseline, the stem cell source alone differed significantly between the steroid-responsive and steroid-refractory groups $(P=0.0406)$.

About aGVHD, the cumulative incidence of grade III-IV aGVHD was $25 \%$ in the steroid-responsive group and $75 \%$ in the steroid-refractory group $(P=0.00136$; Supplementary Table 1). In all organs except the skin, stage III-IV aGVHD involvement was more frequently observed in the steroid-refractory group than in the steroid-sensitive group. The complete response rate at day 28 was $96 \%$ in the steroid-sensitive group and $30 \%$ in the steroid-refractory group (odds ratio $=0.0211,95 \% \mathrm{CI}$ : $0.000430-0.184, P<0.001)$. The cumulative incidence of non-relapse mortality at 12 months was $9.4 \%$ in the steroid-sensitive group and $40 \%$ in the steroid-refractory group $(P=0.00231)$.

All patients underwent at least upper or lower endoscopy, and $43 \%$ underwent both procedures (Table 1). Biopsies were performed in $85 \%$ of upper endoscopies and $100 \%$ of lower endoscopies. Regarding structures targeted by upper and lower endoscopy, the ileum was the most severely involved site (Supplementary Table 2). Interestingly, the macroscopic severity of ileum did not always reflect that of other segments. In $70 \%(7 / 10)$ of cases that grade 4 lesions were observed in ileum macroscopically, the scores of other segments were mild ( 2 or less). Moreover, granulation tissue was a prominent finding in the steroid-refractory group, although this factor was not included in the histopathologic grading criteria.

We next investigated the endoscopic factors that predicted a steroid response in patients with gastrointestinal aGVHD. The univariate analysis indicated that macroscopic findings in the ileum, histologic findings in the ileum and colon, and the presence of granulation were prognostic variables for steroid-refractory gastrointestinal aGVHD (hazard ratio $[\mathrm{HR}]=11.2,95 \%$ confidence interval $[\mathrm{CI}]$ : 2.2-56.9, $P=0.00359 ; \mathrm{HR}=16.9,95 \%$ CI: $2.55-111$, $P=0.00335 ; \mathrm{HR}=4.71,95 \%$ CI: $1.08-20.6, P=0.0395$; $\mathrm{HR}=18.8,95 \%$ CI: $2.11-168, P=0.00854$, respectively) (Table 2). After we adjusted for potential contributing variables as identified by the univariate analysis, multivariate analyses revealed that macroscopic and histologic findings in the ileum and the presence of granulation were associated with steroid-refractory gastrointestinal aGVHD $(\mathrm{HR}=11.7,95 \%$ CI: $1.84-74.2, P=0.00918 ; \mathrm{HR}=13.2$, 95\% CI: $1.5-116, \quad P=0.0201 ; \quad \mathrm{HR}=18.9, \quad 95 \% \quad \mathrm{CI}:$ $1.96-183, P=0.011$, respectively) (Table 2).

In this study, we analyzed all segments targeted by both upper and lower endoscopy and determined that macroscopic and histopathological findings in the terminal ileum were significantly associated with the response to steroids in a multivariate analysis. Other segments did not significantly predict the response to steroids. Previous reports have emphasized the importance of the duodenum or colon with respect to disease severity and outcomes [1-4], and the difference between those conclusions and our findings might be due to a lack of investigation of the terminal ileum via lower endoscopy in earlier studies.

Interestingly, the presence of granulation tissue was significantly associated with steroid-refractory disease. The presence of granulomatous inflammation in the intestine was first reported in the context of cord colitis syndrome, which arises after cord blood transplantation (CBT) [7]. However, a later report stated that granulation is not a specific feature of cord colitis syndrome but is also present in cases of gastrointestinal aGVHD and cytomegalovirus (CMV) colitis [8]. In this study, granulation tissue was observed in only one patient who received CBT. Recent studies have also shown that a selective migration of the ileum by neutrophils is closely associated with aGVHD pathogenesis in mouse models $[9,10]$. We observed neutrophil localization in granulomatous lesions of the ileum (Supplementary Fig. 1e). The reason neutrophil existed only to a certain extent might be that neutrophils were reported to migrate from the ileum to the mesenteric lymph nodes before the onset of aGVHD [10]. Although future studies will need to analyze the pathogenesis of granulation, we have provided new evidence suggesting that granulation is also a useful predictor of disease severity. 
Table 1 Patient and transplant characteristics.

\begin{tabular}{|c|c|c|c|c|c|}
\hline Characteristic & Value $(n=44)$ & Steroid-responsive & Steroid-refractory & Total & $P$ \\
\hline \multicolumn{6}{|l|}{ Age } \\
\hline & Median & 43 & 49 & 47.5 & \multirow[t]{2}{*}{0.86} \\
\hline & Range & $17-68$ & $17-65$ & $17-68$ & \\
\hline \multicolumn{6}{|l|}{ Sex } \\
\hline & Male & 12 & 13 & 25 & \multirow[t]{2}{*}{0.372} \\
\hline & Female & 12 & 7 & 19 & \\
\hline \multicolumn{6}{|l|}{ PS } \\
\hline & 0 & 11 & 9 & 20 & \multirow[t]{3}{*}{0.979} \\
\hline & 1 & 11 & 10 & 21 & \\
\hline & $2-4$ & 2 & 1 & 3 & \\
\hline \multicolumn{6}{|c|}{ Time from transplant to onset of gastrointestinal aGVHD-like symptom } \\
\hline & Median (days) & 32 & 23 & 28 & \multirow[t]{2}{*}{0.203} \\
\hline & Range & $17-91$ & $15-64$ & & \\
\hline \multicolumn{6}{|l|}{ Disease } \\
\hline & AML & 10 & 8 & 18 & \multirow[t]{6}{*}{0.664} \\
\hline & MDS & 6 & 3 & 9 & \\
\hline & ALL & 3 & 3 & 6 & \\
\hline & ML & 4 & 2 & 6 & \\
\hline & CML & 0 & 2 & 2 & \\
\hline & Others & 1 & 2 & 3 & \\
\hline \multicolumn{6}{|l|}{ Disease risk } \\
\hline & High & 10 & 11 & 21 & \multirow[t]{2}{*}{0.545} \\
\hline & Low & 14 & 9 & 23 & \\
\hline \multicolumn{6}{|l|}{ Donor type } \\
\hline & Matched related & 4 & 5 & 9 & \multirow[t]{4}{*}{0.593} \\
\hline & Mismatched related & 2 & 4 & 6 & \\
\hline & Matched unrelated & 13 & 8 & 21 & \\
\hline & Mismatched unrelated & 5 & 3 & 8 & \\
\hline \multicolumn{6}{|c|}{ Stem cell source } \\
\hline & Bone marrow & 19 & 10 & 29 & \multirow[t]{3}{*}{0.0406} \\
\hline & Mobilized blood & 3 & 9 & 12 & \\
\hline & Cord blood & 2 & 1 & 3 & \\
\hline \multicolumn{6}{|c|}{ Conditioning intensity } \\
\hline & Myeloablative & 17 & 17 & 34 & \multirow[t]{2}{*}{0.306} \\
\hline & Reduced intensity & 7 & 3 & 10 & \\
\hline \multicolumn{6}{|l|}{ TBI } \\
\hline & 12 & 13 & 10 & 23 & \multirow[t]{3}{*}{0.758} \\
\hline & $2-4$ & 5 & 2 & 7 & \\
\hline & 0 & 6 & 8 & 14 & \\
\hline ATG/Alemtuz & & 2 & 0 & 2 & \\
\hline \multicolumn{6}{|l|}{ Procedure type } \\
\hline & Upper endoscopy & 13 & 13 & 26 & \\
\hline & Lower endoscopy & 18 & 19 & 37 & \\
\hline \multicolumn{6}{|c|}{ Biopsy performed } \\
\hline & Upper endoscopy & 9 & 13 & 22 & \\
\hline & Lower endoscopy & 18 & 19 & 37 & \\
\hline
\end{tabular}

Factors related to patients, transplantation, and aGVHD were compared between steroid-responsive and steroid-refractory patients, using Fisher's exact test for categorial variables and the Mann-Whitney test for continuous variables.

$A L L$ acute lymphoblastic leukemia, $A M L$ acute myeloid leukemia, $A T G$ antithymocyte globulin, $C M L$ chronic myeloid leukemia, $M D S$ myelodysplastic syndrome, $M L$ malignant lymphoma, $P S$ performance status, $T B I$ total body irradiation.

Our study had some limitations. First, this was a retrospective study of a small number of patients at a single institution. Second, we evaluated the macroscopic and histopathologic findings according to the Cruza and Freiburg criteria, which are commonly referred to in other articles, but did not apply the most recent grading system [11].

In conclusion, although our study is limited by factors inherent to a single-center retrospective analysis, our data 
Table 2 Univariate and multivariate analyses of predictors for steroid-refractory gastrointestinal aGVHD.

\begin{tabular}{|c|c|c|c|c|}
\hline & $\begin{array}{l}\text { Univariate odds } \\
(95 \% \mathrm{CI})\end{array}$ & $\begin{array}{l}\text { Univariate } \\
\text { analysis } P\end{array}$ & $\begin{array}{l}\text { Multivariate odds } \\
(95 \% \text { CI })\end{array}$ & $\begin{array}{l}\text { Multivariate } \\
\text { analysis } P\end{array}$ \\
\hline Sex (male) & $1.86(0.549-6.28)$ & 0.319 & & \\
\hline Age $(\geqq 40$ years $)$ & $1.57(0.464-5.32)$ & 0.468 & & \\
\hline PS $(2-4)$ & $0.579(0.0486-6.90)$ & 0.665 & & \\
\hline Disease risk (high) & $1.71(0.517-5.67)$ & 0.379 & & \\
\hline HLA (match) & $0.765(0.214-2.73)$ & 0.679 & & \\
\hline Donor (related) & $2.450(0.685-8.80)$ & 0.168 & & \\
\hline Conditioning (MAC) & $2.33(0.515-10.6)$ & 0.272 & & \\
\hline Skin involvement & $1.24(0.323-4.72)$ & 0.757 & & \\
\hline Liver involvement & $2.75(0.448-16.90)$ & 0.275 & & \\
\hline \multicolumn{5}{|c|}{ Endoscopic grading $(0-4)$} \\
\hline Stomach & $0.458(0.0363-5.79)$ & 0.547 & & \\
\hline Duodenum & Inf & 0.994 & & \\
\hline Ileum & $11.2(2.2-56.9)$ & 0.00359 & $11.7(1.84-74.2)$ & 0.00918 \\
\hline Colon & $0.313(0.0634-1.54)$ & 0.153 & & \\
\hline Sigmoid colon & $1.24(0.235-6.58)$ & 0.797 & & \\
\hline Rectum & $0.889(0.0513-15.4)$ & 0.935 & & \\
\hline \multicolumn{5}{|c|}{ Histologic grading $(0-4)$} \\
\hline Stomach & $\operatorname{Inf}$ & 0.995 & & \\
\hline Duodenum & Inf & 0.997 & & \\
\hline Ileum & $16.9(2.55-111)$ & 0.00335 & $13.2(1.50-116)$ & 0.0201 \\
\hline Colon & $4.71(1.08-20.6)$ & 0.0395 & & \\
\hline Sigmoid colon & $4.20(0.738-23.9)$ & 0.106 & & \\
\hline Rectum & $2.89(0.568-14.7)$ & 0.201 & & \\
\hline Granulation & $18.8(2.11-168)$ & 0.00854 & $18.9(1.96-183)$ & 0.011 \\
\hline
\end{tabular}

Univariate and multivariate analyses were conducted using logistic regression models of steroid resistance. When conducting analyses according to macroscopic and histopathologic grade, we set a reference point of 3 for the conversion of quantitative variables into binary variables. The multivariate analysis was performed using variables that were identified as having a $P$ value 0.3 in the univariate analysis.

Inf infinite, MAC myeloablative conditioning. provide new information about the potential usefulness of endoscopy, especially with respect to the role of the terminal ileum in response to steroid therapy.

Acknowledgements We thank the patients and the endoscopy staffs in Jichi Medical University Hospital.

\section{Compliance with ethical standards}

Conflict of interest The authors declare that they have no conflict of interest.

Publisher's note Springer Nature remains neutral with regard to jurisdictional claims in published maps and institutional affiliations.

\section{References}

1. Daneshpouy M, Socie G, Lemann M, Rivet J, Gluckman E, Janin A. Activated eosinophils in upper gastrointestinal tract of patients with graft-versus-host disease. Blood. 2002;99:3033-40.
2. Socié G, Mary JY, Lemann M, Daneshpouy M, Guardiola P, Meignin V, et al. Prognostic value of apoptotic cells and infiltrating neutrophils in graft-versus-host disease of the gastrointestinal tract in humans: TNF and Fas expression. Blood. 2004;103:50-7.

3. Levine JE, Huber E, Hammer STG, Harris AC, Greenson JK, Braun TM, et al. Low Paneth cell numbers at onset of gastrointestinal graft-versus-host disease identify patients at high risk for nonrelapse mortality. Blood. 2013;122:1505-9.

4. Melson J, Jakate S, Fung H, Arai S, Keshavarzian A. Crypt loss is a marker of clinical severity of acute gastrointestinal graft-versushost disease. Am J Hematol. 2007;82:881-6.

5. Sugihara Y, Hiraoka S, Fujii N, Takashima S, Yamasaki Y, Inokuchi $\mathrm{T}$, et al. Villous atrophy in the terminal ileum is a specific endoscopic finding correlated with histological evidence and poor prognosis in acute graft-versus-host disease after allo-hematopoietic stem cell transplantation. BMC Gastroenterol. 2018;18:1-9.

6. Cruz-Correa M, Poonawala A, Abraham SC, Wu TT, Zahurak M, Vogelsang G, et al. Endoscopic findings predict the histologic diagnosis in gastrointestinal graft-versus-host disease. Endoscopy. 2002;34:808-13.

7. Herrera AF, Soriano G, Bellizzi AM, Hornick JL, Ho VT, Ballen $\mathrm{KK}$, et al. Cord colitis syndrome in cord-blood stem-cell transplantation. N. Engl J Med. 2011;365:815-24. 
8. Shimoji S, Kato K, Eriguchi Y, Takenaka K, Iwasaki H, Miyamoto $\mathrm{T}$, et al. Evaluating the association between histological manifestations of cord colitis syndrome with GVHD. Bone Marrow Transpl. 2013;48:1249-52.

9. Schwab L, GoroncyL, Palaniyandi S, Gautam S, Triantafyllopoulou A, Mocsai A, et al. Neutrophil granulocytes recruited upon translocation of intestinal bacteria enhance graft-versus-host disease via tissue damage. Nat Med. 2014;20:648-54.
10. Hülsdünker J, Ottmüller KJ, Neeff HP, Koyama M, Gao Z, Thomas OS, et al. Neutrophils provide cellular communication between ileum and mesenteric lymph nodes at graft-versus-host disease onset. Blood. 2018;131:1858-69.

11. Myerson D, Steinbach G, Gooley TA, Shulman HM. Graftversus-host disease of the gut: a histologic activity grading system and validation. Biol Blood Marrow Transpl. 2017;23:1573-9. 